\title{
Soil depth: an overriding factor for distribution of arbuscular mycorrhizal fungi
}

\author{
A. Shukla ${ }^{*}$, D Vyas $^{1}$, Anuradha Jha ${ }^{2}$ \\ ${ }^{1}$ Laboratory of Microbial Technology and Plant Pathology, Department of Botany, Dr Hari Singh Gour Central University, Sagar \\ 470 003, Madhya Pradesh, India; ' ${ }^{2}$ ational Research Centre for Agroforestry, Opposite Pahuj Dam, Gwalior Road, Jhansi 284 \\ 003, Uttar Pradesh, India.*Corresponding author: ashokshukla06@gmail.com
}

\begin{abstract}
Present study deals with the distribution and diversity of arbuscular mycorrhizal fungi (AMF) in naturally growing Withania somnifera and Ocimum sanctum. Variations in soil $\mathrm{pH}$ and moisture content (\%) at different soil depths $(0-10,10-20,20-30$ and $30-40 \mathrm{~cm})$ and their possible influences on AMF spore populations were studied at two sites i.e. Jaitpur and Karaiya. A total of 27 AMF species (8 Acaulospora, 1 Cetraspora, 1 Claroideoglomus, 1 Entrophospora, 1 Funneliformis, 13 Glomus, 1 Simiglomus and 1 Septoglomus) were identified. Results revealed that $W$. somnifera harbors relatively more AMF species (21) than O. sanctum (14). Acaulospora scrobiculata, Sep. deserticola and Sim. hoi dominated the rhizosphere of W. somnifera, while A. scrobiculata, Sep. deserticola and G. fasciculatum were predominant in $O$. sanctum. Spore populations, soil $\mathrm{pH}$ and moisture content varied significantly across soil depths. Moreover, the ability of soil to support AMF population decreased significantly with increased soil depth. Results clearly indicated the involvement of factor other than soil $\mathrm{pH}$ and moisture content in AMF distribution. Thus, it may be stated that overriding factor was depth, and this can be justified by fewer roots and fewer mycorrhizae in deeper soil layers.
\end{abstract}

Keywords: Arbuscular mycorrhiza, moisture content, shannon-weaver index, Ocimum sanctum, Withania somnifera.

\section{Introduction}

Arbuscular mycorrhizal fungi (AMF) are below ground symbiotic associations between plant roots and fungi (Shukla et al., 2012a) which adds dimension to the plant-soil-microbe systems. AMF are able to develop associations with more than $80 \%$ of vascular or non-vascular terrestrial plants (Brundrett, 2002). These are recognized as an important component of soil ecosystem (Oehl et al., 2004 and 2005; Shukla et al., 2012b). AMF can improve plant growth under low fertility conditions, improve water balance of the plants and help plants to establish in new areas (Jha et al., 2011; Shukla et al., 2012c). Distribution of AMF is a result of contemporary ecological processes (Shukla et al., 2009). Several factors viz., soil pH, moisture content, soil disturbances and above-ground vegetations determine its distribution (Yang et al., 2010; Sturmer and Siqueira, 2011). According to Smith and Read (2008), AMF are ubiquitous in occurrence, 
but there are some conflicting reports regarding its association with medicinal plants. Previous studies suggested the absence of AMF in such plants (Kumar and Mahadevan, 1984) but later on the association of these fungi with medicinal plants were widely studied (Copetta et al., 2006; Soni and Vyas, 2007; Zubek and Blaszkowski, 2009; Mishra et al.,2011).

Medicinal plants are the sources of several pharmaceutically important compounds which play a vital role in human health care. According to World Health Organization (WHO), more than $80 \%$ of the world's population relies on the use of traditional medicines for their primary healthcare (Radhika and Rodrigues, 2010). Withania somnifera (L.) Dunal (Indian Ginseng) and Ocimum sanctum L. (Holy Basil) are two most important medicinal plants. Both the plant species are being utilized for the treatment of various ailments since time immemorial. They are wildly grown in warmer parts of India especially in Madhya Pradesh of Bundelkhand region (Khare, 2004; Soni and Vyas, 2007). Due to growing recognition of natural products, their non-toxicity and easy availability, the demand of these plants are being increased (Kapoor, 2005), and to fulfill this demand, locally collected plants are being exploited commercially for the preparation of medicines (Misra and Gupta, 2010).

In India, most of the knowledge regarding association of AMF with medicinal plants comes from arid region, western and southern parts of India (Khade et al., 2002; Muthukumar et al., 2006; Panwar and Tarafdar, 2006; Kumar et al., 2010; Radhika and Rodrigues, 2010). The literature survey clearly indicates that there is much to be learnt from the soil about association of AMF with $W$. somnifera and $O$. sanctum. Furthermore, systematic work on mycorrhizal investigations regarding these plant species has not been conducted in Central India. Therefore, an extensive investigation was carried out to determine the distribution and diversity of AMF in these plants over the range of soil depth (up to 40 $\mathrm{cm})$. For the present investigation, two sites i.e. Jaitpur and Karaiya of Sagar district were selected because the edaphic factors of these sites showed variable soil textures.

\section{Materials and methods}

\subsection{Site description}

Present study was carried out at Dr. Hari Singh Gour Central University, Sagar, India. The region $\left(23^{\circ} 10^{\prime}-\right.$ $24^{\circ} 27^{\prime} \mathrm{N}$ latitude and $78^{\circ} 4^{\prime}-79^{\circ} 21^{\prime}$ E longitude) is situated between North of Tropic of Cancer on an average altitude of $580 \mathrm{~m}$ above mean sea level. Sagar lies in Agro-ecoregion 10; Central Highlands, Hot Sub-Humid Ecoregion with medium and deep black soils (I5C3) (Sehgal et al., 1990). The region has monsoonal climate where $90 \%$ of the annual rainfall takes place during the southwest monsoon period (June to September). The mean annual rainfall of the region is $1234 \mathrm{~mm}$. January is the coldest while May and June are the hottest months. The maximum recorded temperature on a particular day often touches $47-48{ }^{\circ} \mathrm{C}$ during summer.

In order to study the AMF diversity of $W$. somnifera and $O$. sanctum, five naturally growing plants of each species (almost similar age groups) were marked at Jaitpur and Karaiya, respectively. It is worth mention that no other plants were growing in the close proximity of selected plants. The main soil type at Jaitpur was vertisol (mixture of clay and loam), highly water retentive; its $\mathrm{pH}\left(1: 2.5 \mathrm{H}_{2} \mathrm{O}\right)$ varied from 6.25 to 7.16 and organic carbon varied from 0.45 to $0.70 \%$. While, at Karaiya, soil was alfisol (gravelly in texture), $\mathrm{pH}$ varied from 6.38 to 7.24 and organic carbon varied from 0.38 to $0.65 \%$. (Table 1 ). The test sites were open and the process of retention of rain water was very poor. At selected sites, rainfed conditions were prevailing.

\subsection{Sampling, extraction and identification of $A M F$}

To isolate AMF spores, soil samples were collected at different depths viz., 0-10, 10-20, 20-30 and 30-40 cm in triplicates in the month of October 2010. Samples were taken as close as possible to the base of the plant ( 0 to $15 \mathrm{~cm}$ from stem) by removing the topsoil. From each of the five plants, three soil core samples (100 g 
each) were collected with the help of a corer. Collected samples were kept in sealed polyethylene bags, labeled and brought to the laboratory, where these were airdried and ground through a $2 \mathrm{~mm}$ sieve for further analyses. Then, all the three rooting-zone soil samples were mixed thoroughly to make a composite sample (300 g approximately). Briefly, $50 \mathrm{~g}$ samples were taken in $1 \mathrm{~L}$ water and decanted through a series of sieves (mesh size: 250, 150 and $53 \mu$ ). Sievings were individually collected in separate jars and transferred onto the grided petri dish $(11 \mathrm{~cm})$, for microscopic observations. AMF spores were counted and isolated following the procedure of Gerdemann and Nicolson (1963). The isolated spores were mounted on glass slides in polyvinyl-lactoglycerol (PVLG) or Melzer's reagent and examined microscopically; then identified using information from INVAM website (http://invam. caf.wvu.edu). The latest taxonomic classifications of AMF (Oehl et al., 2008 and 2011) were used to place the identified AMF species in correct genera.

Number of AMF species (richness) at different depths/ sites and frequency of occurrence (\%) were also calculated. Shannon-weaver diversity index $\left(\mathrm{e}^{\mathrm{H}}\right)$ was determined as an additional measure, as it combines two components of diversity i.e. $\mathrm{e}^{\mathrm{H}^{\prime}}$ and species evenness ( $\left.E^{\prime}\right)$. It was calculated from the equation $\mathrm{H}^{\prime}=-\Sigma \rho i \ln$ where $\rho \mathrm{i}$ is the relative spore abundance of the $i^{\text {th }}$ species compared to all species identified in a sample (Shannon and Weaver, 1946).

\subsection{Soil analyses for $p H$ and moisture content}

Soil $\mathrm{pH}$ was measured with glass electrode $\mathrm{pH}$ meter using 1:2.5 soil-water ratio (Richards, 1954) in samples taken from the test plant species at different soil depths at each site. A separate soil sampling was carried out from each marked plants at different soil depths, for the estimation of moisture content. Collected samples were kept in separate aluminium boxes, labeled and brought to the laboratory. Moisture content of soil was determined gravimetrically by using the formula: Moisture $(\%)=$ Fresh weight of soil - Dry weight of soil/Dry weight of soil x 100 .

\subsection{Statistical analysis}

All the data were analyzed statistically by using SYSTAT version 12 . The graphs were prepared by SYSTAT.

\section{Results}

\subsection{Occurrence, species richness and diversity of AMF}

AMF spores were separately isolated and identified from the soil samples taken from the investigated plants at different soil depths at each site. A total of 27 AMF species belonging to 8 different genera, were identified (Table 2). Of these, 8 belonged to Acaulospora, 1 to Cetraspora, 1 to Claroideoglomus, 1 to Entrophospora, 1 to Funneliformis, 13 to Glomus, 1 to Simiglomus and 1 to Septoglomus. Six AMF spores i.e. Acaulospora sp 1, Acaulospora sp 2, Glomus sp 1, Glomus sp 2, Glomus sp 3 and Glomus sp 4, could not or not clearly be attributed to species level so far. Results revealed that $W$. somnifera harbors relatively more AMF species (21) than $O$. sanctum (14).

Acaulospora scrobiculata, Acaulospora sp 2, G. aggregatum, Sep. deserticola, C. etunicatum, G. fasciculatum, Sim. hoi and G. intraradices were found to be associated with both plant species (Table 2). Few AMF species were exclusively recovered from W. somnifera while, few were specific to $O$. sanctum. Acaulospora scrobiculata, Sep. deserticola, Sim. hoi, G. intraradices, F. mosseae and Acaulospora sp 1 were predominantly present in rhizosphere of $W$. somnifera (explaining $100-75 \%$ frequency of occurrence). Similarly, A. scrobiculata, Sep. deserticola and G. fasciculatum were dominant $(87.5 \%)$ in $O$. sanctum. Richest AMF diversity was reported from surface soil $(0-10 \mathrm{~cm})$.

The AMF diversities, expressed by Shannon-weaver index are presented in Table 3. In W. somnifera, Karaiya soil harbors more diverse AMF species (eH'1.87) than Jaitpur ( $\left.\mathrm{e}^{\mathrm{H}^{\prime}}-1.74\right)$. However, in O. sanctum, 
Table1. Soils properties at different depths (cm) of Withania somnifera and Ocimum santum at different sites (Jaitpur and Karaiya).

\begin{tabular}{|c|c|c|c|c|c|c|c|c|c|c|c|}
\hline \multirow{2}{*}{$\begin{array}{l}\text { Plant } \\
\text { species }\end{array}$} & \multirow{2}{*}{$\begin{array}{l}\text { Soil } \\
\text { depth } \\
\text { (cm) }\end{array}$} & \multicolumn{5}{|c|}{ Jaitpur } & \multicolumn{5}{|c|}{ Karaiya } \\
\hline & & $\begin{array}{l}\text { pH } \\
(1: 2.5 \\
\left.\mathrm{H}_{2} \mathrm{O}\right)\end{array}$ & $\begin{array}{l}\mathrm{EC} \\
\left(\mu \mathrm{S} \mathrm{cm} \mathrm{cm}^{-1}\right)\end{array}$ & $\begin{array}{l}\text { OC } \\
(\%)\end{array}$ & $\begin{array}{l}\text { Olsen } \\
\text { P } \\
(p p m)\end{array}$ & $\begin{array}{l}\text { Moisture } \\
\text { content } \\
(\%)\end{array}$ & $\begin{array}{l}\text { pH } \\
(1: 2.5 \\
\left.\mathrm{H}_{2} \mathrm{O}\right)\end{array}$ & $\begin{array}{l}\mathrm{EC} \\
\left.(\mu \mathrm{S} \mathrm{cm})^{-1}\right)\end{array}$ & $\begin{array}{l}\text { OC } \\
(\%)\end{array}$ & $\begin{array}{l}\text { Olsen } \\
\text { P } \\
\text { (ppm) }\end{array}$ & $\begin{array}{l}\text { Moisture } \\
\text { content } \\
(\%)\end{array}$ \\
\hline$W$. & $0-10$ & 7.00 & 27.0 & 0.67 & 5.4 & 2.97 & 6.87 & 19.6 & 0.65 & 4.0 & 2.80 \\
\hline \multirow[t]{3}{*}{ somnifera } & $10-20$ & 6.90 & 26.7 & 0.55 & 5.5 & 3.30 & 6.73 & 23.3 & 0.61 & 4.3 & 3.00 \\
\hline & $20-30$ & 6.50 & 29.2 & 0.52 & 5.5 & 3.50 & 6.60 & 24.8 & 0.55 & 5.7 & 3.43 \\
\hline & $30-40$ & 6.40 & 32.1 & 0.45 & 6.0 & 3.80 & 6.50 & 27.9 & 0.38 & 7.2 & 3.63 \\
\hline \multirow[t]{4}{*}{ O. sanctum } & $0-10$ & 6.93 & 23.4 & 0.70 & 3.9 & 2.87 & 7.17 & 24.3 & 0.64 & 5.3 & 3.17 \\
\hline & $10-20$ & 6.83 & 24.2 & 0.61 & 4.3 & 2.97 & 7.10 & 24.8 & 0.57 & 6.1 & 3.30 \\
\hline & $20-30$ & 6.70 & 27.1 & 0.58 & 4.4 & 3.33 & 7.03 & 31.2 & 0.50 & 7.0 & 3.53 \\
\hline & $30-40$ & 6.60 & 27.9 & 0.51 & 4.7 & 3.57 & 6.87 & 30.1 & 0.44 & 8.3 & 3.93 \\
\hline
\end{tabular}

All the values are means of the three replications $(n=3)$ Legend:EC=Electrical conductivity $. \mathrm{OC}=$ Organic carbon, Olsen $\mathrm{P}$ : Olsen phosphorus.

Table 2a. Occurrence of AMF species at different soil depths $(\mathrm{cm})$ of Withania somnifera and Ocimum sanctum at different sites (Jaitpur and Karaiya).

\begin{tabular}{|c|c|c|c|c|c|c|c|c|c|}
\hline \multirow{3}{*}{ AMF species } & \multicolumn{8}{|c|}{ Withania somnifera } & \multirow{3}{*}{$\begin{array}{l}\text { Frequency } \\
(\%)\end{array}$} \\
\hline & \multicolumn{4}{|c|}{ Jaitpur } & \multicolumn{4}{|c|}{ Karaiya } & \\
\hline & $0-10$ & $10-20$ & 20-30 & $30-40$ & $0-10$ & $10-20$ & $20-30$ & $30-40$ & \\
\hline Acaulospora bireticulata & & & & & $x^{a}\left(12^{b}\right)$ & & & & 12.5 \\
\hline A. denticulata & & & & & & $\mathrm{x}(9)$ & $\mathrm{x}(15)$ & & 25.0 \\
\hline A. dilatata & & & & & & & & & - \\
\hline A. longula & & & & & & & & & - \\
\hline A. mellea & $\mathrm{x}(4)$ & $\mathrm{x}(21)$ & & $\mathrm{x}(6)$ & & & & & 37.5 \\
\hline A. scrobiculata & $x(33)$ & $\mathrm{x}(81)$ & $x(30)$ & $x(18)$ & $x(39)$ & $x(27)$ & $\mathrm{x}(9)$ & $x(18)$ & 100.0 \\
\hline Acaulospora sp 1 & $\mathrm{x}(18)$ & & $\mathrm{x}(9)$ & & $x(6)$ & $\mathrm{x}(3)$ & $\mathrm{x}(3)$ & $x(6)$ & 75.0 \\
\hline Acaulospora $\mathrm{sp} 2$ & $\mathrm{x}(9)$ & $\mathrm{x}(18)$ & & & & & & & 25.0 \\
\hline Cetrospora pellucida & & & & & & & & & - \\
\hline Claroideoglomus etunicatum & $\mathrm{x}(6)$ & $\mathrm{x}(9)$ & $\mathrm{x}(15)$ & & & & & & 37.5 \\
\hline Entrophospora infrequense & & & & & & & & & - \\
\hline Funneliformis mosseae & $\mathrm{x}(54)$ & $\mathrm{x}(24)$ & $\mathrm{x}(12)$ & & $\mathrm{x}(12)$ & $\mathrm{x}(9)$ & $\mathrm{x}(3)$ & & 75.0 \\
\hline Glomus aggregatum & & $\mathrm{x}(21)$ & & & $x(12)$ & $\mathrm{x}(3)$ & & & 37.5 \\
\hline G. arborense & $\mathrm{x}(9)$ & & & & $x(3)$ & & & & 25.0 \\
\hline G. cerebriforme & & & & & & & & & - \\
\hline G. diaphanum & & & & & $x(6)$ & & & & 12.5 \\
\hline G. fasciculatum & $\mathrm{x}(18)$ & $\mathrm{x}(9)$ & & & $\mathrm{x}(9)$ & $x(3)$ & & & 50.0 \\
\hline G. intraradices & $\mathrm{x}(27)$ & $\mathrm{x}(3)$ & $\mathrm{x}(21)$ & $\mathrm{x}(6)$ & $x(21)$ & $x(15)$ & $\mathrm{x}(3)$ & & 87.5 \\
\hline G. invermayanum & & & & & & & & & - \\
\hline G. pansihalos & $\mathrm{x}(6)$ & $\mathrm{x}(3)$ & & & $\mathrm{x}(9)$ & & & & 37.5 \\
\hline G. vesiculiferum & $x(12)$ & $x(3)$ & $x(18)$ & & & $x(6)$ & & & 50.0 \\
\hline Glomus sp 1 & $x(24)$ & & $x(3)$ & & & $\mathrm{x}(12)$ & $\mathrm{x}(3)$ & & 50.0 \\
\hline Glomus sp 2 & $\mathrm{x}(12)$ & $\mathrm{x}(3)$ & & $\mathrm{x}(3)$ & $\mathrm{x}(12)$ & & & & 50.0 \\
\hline Glomus sp 3 & $\mathrm{x}(15)$ & $\mathrm{x}(12)$ & & & & & & & 25.0 \\
\hline Glomus sp 4 & $x(15)$ & $\mathrm{x}(18)$ & & & & & & & 50.0 \\
\hline Septoglomus deserticola & $\mathrm{x}(30)$ & $\mathrm{x}(3)$ & $\mathrm{x}(21)$ & $\mathrm{x}(24)$ & $x(54)$ & $\mathrm{x}(21)$ & $\mathrm{x}(33)$ & $\mathrm{x}(9)$ & 100.0 \\
\hline Simiglomus hoi & $x(66)$ & $x(6)$ & $x(27)$ & $\times(9)$ & $x(36)$ & $x(63)$ & $x(42)$ & $x(18)$ & 100.0 \\
\hline Species richness & $17(358)$ & $15(234)$ & $9(156)$ & $6(66)$ & $13(231)$ & $11(171)$ & $8(111)$ & $4(51)$ & \\
\hline
\end{tabular}

a.Present. $b$ Figures in the parenthesis indicate total number of spores of particular AMF species $(n=3)$ 
Table 2b. Occurrence of AMF species at different soil depths (cm) of Withania somnifera and Ocimum sanctum at different sites (Jaitpur and Karaiya).

\begin{tabular}{|c|c|c|c|c|c|c|c|c|c|}
\hline \multirow[t]{3}{*}{ AMF species } & \multicolumn{6}{|c|}{ Ocimum sanctum } & & & \multirow{3}{*}{$\begin{array}{l}\text { Frequency } \\
(\%)\end{array}$} \\
\hline & \multicolumn{4}{|l|}{ Jaitpur } & \multicolumn{4}{|l|}{ Karaiya } & \\
\hline & $0-10$ & $10-20$ & 2030 & $30-40$ & $0-10$ & $10-20$ & $20-30$ & $30-40$ & \\
\hline Acaulospora bireticulata & & & & & & & & & - \\
\hline A. denticulata & & & & & & & & & - \\
\hline A. dilatata & $\mathrm{x}(18)$ & $\mathrm{x}(36)$ & & & & & & & 25.0 \\
\hline A. longula & $\mathrm{x}(33)$ & & $\mathrm{x}(3)$ & $x(21)$ & $x(12)$ & $\mathrm{x}(30)$ & $\mathrm{x}(18)$ & & 75.0 \\
\hline A. mellea & & & & & & & & & - \\
\hline A. scrobiculata & $\mathrm{x}(69)$ & $\mathrm{x}(42)$ & $\mathrm{x}(9)$ & & $\mathrm{x}(48)$ & $\mathrm{x}(9)$ & $\mathrm{x}(12)$ & $\mathrm{x}(12)$ & 87.5 \\
\hline Acaulospora sp 1 & & & & & & & & & - \\
\hline Acaulospora sp 2 & $\mathrm{x}(9)$ & & $\mathrm{x}(24)$ & & $\mathrm{x}(21)$ & $\mathrm{x}(24)$ & & & 50.0 \\
\hline Cetrospora pellucida & & & & $\mathrm{x}(6)$ & & & $\mathrm{x}(30)$ & $\mathrm{x}(27)$ & 37.5 \\
\hline Claroideoglomus etunicatum & $x(21)$ & $\mathrm{x}(12)$ & & & & & & & 25.0 \\
\hline Entrophospora infrequense & & & $\mathrm{x}(9)$ & $\mathrm{x}(3)$ & & & & & 25.0 \\
\hline Funneliformis mosseae & & & & & & & & & - \\
\hline Glomus aggregatum & $\mathrm{x}(6)$ & $\mathrm{x}(9)$ & & & $x(6)$ & $\mathrm{x}(9)$ & & & 50.0 \\
\hline G. arborense & & & & & & & & & - \\
\hline G. cerebriforme & & $\mathrm{x}(18)$ & & & $\mathrm{x}(15)$ & & & & 25.0 \\
\hline G. diaphanum & & & & & & & & & - \\
\hline G. fasciculatum & $x(54)$ & $x(24)$ & $x(18)$ & x (33) & $x(63)$ & $x(24)$ & $\mathrm{x}(9)$ & & 87.5 \\
\hline G. intraradices & $\mathrm{x}(18)$ & $\mathrm{x}(30)$ & $\mathrm{x}(21)$ & $x(24)$ & $\mathrm{x}(27)$ & $x(6)$ & & & 75.0 \\
\hline G. invermayanum & $\mathrm{x}(39)$ & $\mathrm{x}(33)$ & $\mathrm{x}(39)$ & & $\mathrm{x}(12)$ & $x(12)$ & $\mathrm{x}(6)$ & & 75.0 \\
\hline G. pansihalos & & & & & & & & & - \\
\hline G. vesiculiferum & & & & & & & & & - \\
\hline Glomus sp 1 & & & & & & & & & - \\
\hline Glomus sp 2 & & & & & & & & & - \\
\hline Glomus sp 3 & & & & & & & & & - \\
\hline Glomus sp 4 & & & & & & & & & - \\
\hline Septoglomus deserticola & $x(21)$ & $\mathrm{x}(51)$ & $\mathrm{x}(6)$ & & $\mathbf{x}(39)$ & $\mathrm{x}(6)$ & $x(24)$ & $\mathrm{x}(24)$ & 87.5 \\
\hline Simiglomus hoi & $\mathrm{x}(27)$ & $\mathrm{x}(21)$ & $\mathrm{x}(12)$ & & $x(6)$ & $x(33)$ & $x(3)$ & & 75.0 \\
\hline Species richness & $11(315)$ & $10(276)$ & $9(141)$ & $5(87)$ & $10(249)$ & $9(153)$ & $7(102)$ & $3(63)$ & \\
\hline
\end{tabular}

greater index was observed at Jaitpur $\left(\mathrm{e}^{\left.\mathrm{H}^{\prime}-2.48\right)}\right.$ as compared to Karaiya (eH'- 2.33).

\subsection{AMF spore population, $\mathrm{pH}$ and moisture content of soil}

Spore populations varied significantly $(p<0.05)$ across various soil depths (Figure 1). Maximum number of spores was recorded from upper soil $(0-10 \mathrm{~cm})$ as compared to samples analyzed from the deeper layers (Table 2). In general, the ability of soil to support AMF populations significantly decreased with increase in soil depths. Irrespective of plant species, higher spore population was observed at Karaiya as compared to Jaitpur.

A decrease in soil $\mathrm{pH}$ with increasing soil depths was observed (Figure 1). In W. somnifera, comparison between studied sites could not be made, while in $O$. sanctum, significantly higher $\mathrm{pH}$ was observed at Karaiya. On the contrary, moisture content increased with increase in soil depths. Significant differences were noticed at different soil depths and sites. In $W$. somnifera, significantly higher value was observed at Jaitpur, while in case of $O$. sanctum, it was higher at Karaiya. 
Table 3. Shannon-weaver diversity index at different soil depths $(\mathrm{cm})$ of Withania somnifera and Ocimum sanctum at different sites (Jaitpur and Karaiya).

\begin{tabular}{lcc}
\hline Soil depth $(\mathbf{c m})$ & \multicolumn{2}{c}{ Shannon Weaver Index $\left(\mathbf{e}^{\mathbf{H}}\right)$} \\
\cline { 2 - 3 } & Jaitpur & Karaiya $^{\mathbf{x}}$ \\
\hline Withania somnifera & & \\
$0-10$ & 1.73 & 1.72 \\
$10-20$ & 1.65 & 1.80 \\
$20-30$ & 1.70 & 1.94 \\
$30-40$ & 1.89 & 2.00 \\
Mean & 1.74 & 1.87 \\
Ocimum sanctum & & \\
$0-10$ & 1.93 & 1.84 \\
$10-20$ & 1.65 & 1.89 \\
$20-30$ & 2.55 & 2.60 \\
$30-40$ & 3.79 & 3.00 \\
Mean & 2.48 & 2.33 \\
\hline
\end{tabular}
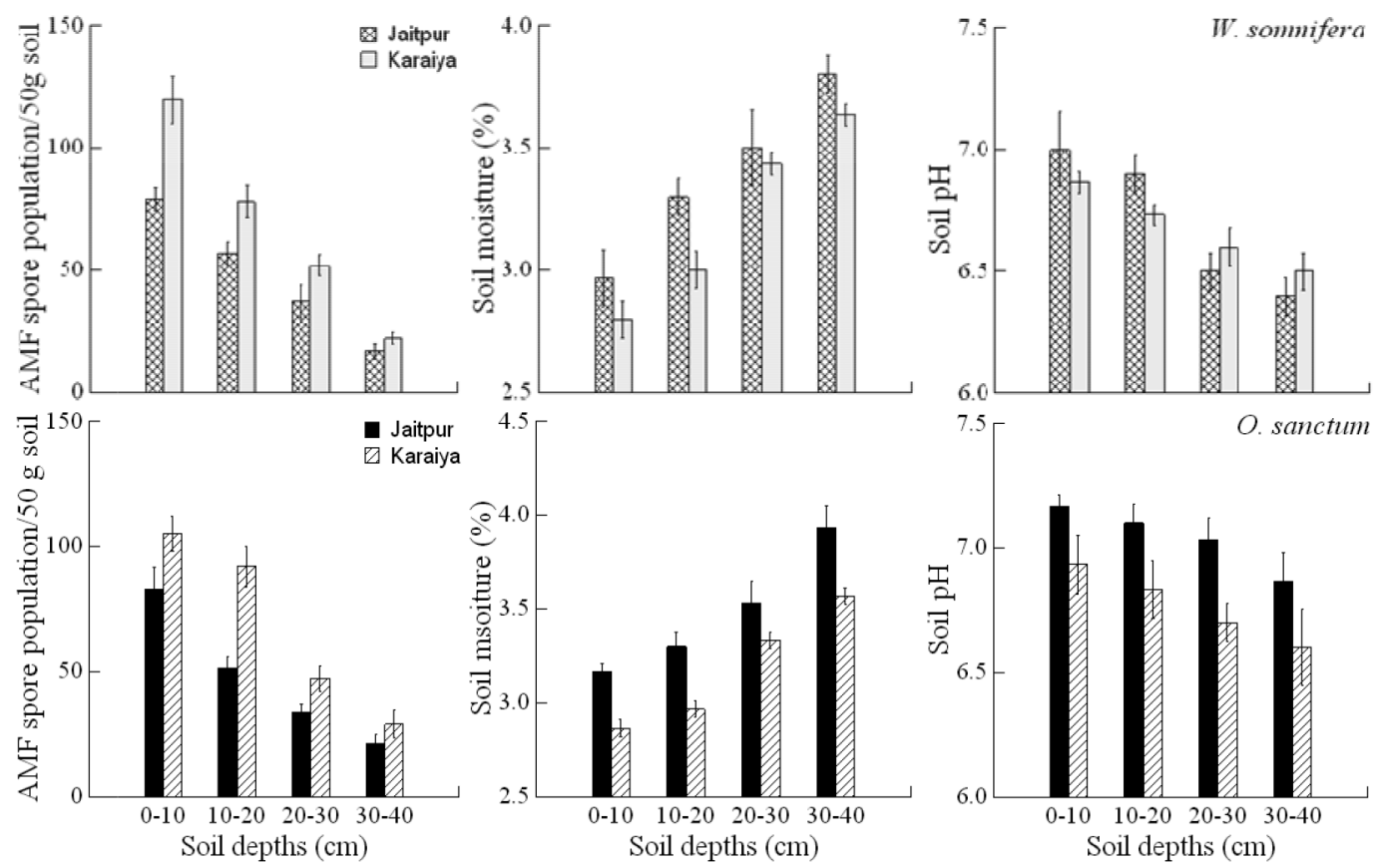

Figure 1. AMF spore population (50 $\mathrm{g}^{-1}$ soil), soil moisture (\%) and soil $\mathrm{pH}$ at different soil depths of Withania somnifera and Ocimum sanctum at Jaitpur and Karaiya. 


\section{Discussion}

In present study, some common as well as some different AMF species were found associated with medicinal plants at sites with different soil structures. Results suggested that AMF composition changed with soil depths, and spore population decreased with increase in depth. Our findings corroborated the previous results (Jakobsen and Nielsen, 1983; Zajicek et al., 1986; Bellgrad, 1993; Cuenca and Lovera, 2010). Some researchers suggested that it might be due to the less organic content (Oehl et al., 2005) and low availability of oxygen in deeper soil zones (Verma et al., 2010), because fungi are sensitive to low oxygen pressure which prevails at depth (Brady and Weil, 1996). According to Anderson et al. (1987), AMF are generally scarce where the plant roots are sparse. Moreover, as we already mentioned that no other plant species were growing in close proximity of the investigated plants; hence, we negated the influence of other plant species because earlier we have reported the effect of one plant on AMF biological activities of other plant i.e. plant-plant interaction (Shukla et al., 2012b). Thus, the reduction in AMF spore population with increasing soil depth can also be explained on the basis of fewer roots in deeper soil layers (Cuenca and Lovera, 2010). Considering the results, Glomus was the predominant genus, followed by Acaulospora. The pre-dominant occurrence of Glomus species showed their remarkable adaptation to the drastic condition of our region i.e. Bundelkhand, Central India (Soni and Vyas, 2007; Jha et al. 2011). Results also suggested that $A$. scrobiculata, Acaulospora sp 1, G. aggregatum, Sep. deserticola, C. etunicatum, Sim. hoi and $G$. intraradices, were very frequent in their occurrence. Oehl et al. (2003) called such AMF species as "AMF generalists". Our observations are consistent with the findings of Opik et al. (2006). According to them, some AMF species such as G. mosseae (now F. mosseae), G. intraradices and G. etunicatum (now C. etunicatum) have global distribution. Moreover, some AMF species were common through out the soil depths, while few were depth specific, for example E. infrequense and $\mathrm{Ce}$. pellucida recovered from deeper zones. Thus, at least with respect to the spore formation, these species appear to be specialized for deeper soil layers (Oehl et al., 2005). Our results are in good accord with Mader et al. (2002) and Jansa et al. (2003). Occurrence of Ce. pellucida in deeper zones can be explained on the basis of reduced soil disturbances (Oehl et al., 2005). Furthermore, few AMF species specifically occurred at Jaitpur while few at Karaiya and this can be due to the variations in soil structures at different sites (Land and Schonbeck, 1999; Meyer et al., 2005; Karaarslan and Uyanoz, 2011).

When between-site comparisons were made for both the investigated plants, it was observed that AMF spore population was significantly higher at Karaiya as compared to Jaitpur, irrespective of soil depths. Such variation in AMF population at both the sites is attributed to the different soil properties (Meyer et al., 2005; Karaarslan and Uyanoz, 2011) and soil moisture content (Shukla et al., 2012c). Since, Karaiya soil was gravelly, more aerated and low water retentive therefore provided enough space for AMF sporulation. On the contrary, Jaitpur soil was a mixture of clay and loam hence did not provide enough space for AMF proliferation. Clay has capacity to retain water therefore moisture remains in the soil for more time which might affect the AMF sporulation (Dubey et al., 2008). Schellenbaum et al. (1998) suggested that availability of moisture increases the growth of fungal mycelium for root colonization, leading to a decrease on AMF spore germination.

Our results indicated that soil $\mathrm{pH}$ decreased with increase in soil depth and this can be due to the percolation of water to the deeper zones which leads to the formation of acids (Habte, 1999). AMF spore population was found to be positively correlated with soil $\mathrm{pH}$. Our findings are contradictory to the results of Friese and Koske (1991). They did not find any relationship between sporulation and soil $\mathrm{pH}$. According to Bagyaraj (1991), the interpretation of effect of $\mathrm{pH}$ on AMF population is very difficult, because most of the soil chemical properties change 
with the variation in soil $\mathrm{pH}$. Further, soil moisture content increased with increase in soil depths, and AMF population was negatively correlated with moisture content. Anderson et al. (1983) and Udaiyan et al. (1996) also recorded the negative correlation between AMF population and soil moisture. Recently, we noticed that soil moisture levels (either wet or dry) significantly influence the mycorrhization (spore population and percent root colonization) of the plants at their early growth stage (Shukla et al., 2012c). Peat and Fitter (1993) did not found any relationship between soil moisture and mycorrhization. We assumed that direct cause and effect relationships between soil $\mathrm{pH} /$ moisture content and AMF sporulation are equivocal.

\section{Conclusion}

The, results suggested that AMF are well distributed on medicinal plants in Central Indian Vertisol and Alfisol. Population of AMF, frequency of occurrence and distribution of AMF at studied sites varied with soil depths, soil $\mathrm{pH}$ and moisture content. Results indicated the involvement of factors other than soil $\mathrm{pH}$ and moisture content in the distribution of AMF. Therefore, in short it may be stated that overriding factor is depth which can be justified simply by fewer roots, fewer mycorrhiza and fewer propagules in deeper soil zone to contribute AMF population.

\section{Acknowledgements}

This manuscript is based upon work supported by the University Grants Commission (UGC), New Delhi, India. Ashok Shukla gratefully acknowledges UGC-Dr DS Kothari PDF Scheme [Sanction No. 4-2/2006(BSR)/13-255/2008(BSR)], Government of India for providing financial support. Thanks are also due to anonymous reviewers for critical comments and suggestions.

\section{References}

Anderson, E.L., Millner, P.D., Kunishi, H.M. 1987. Maize root length density and Mycorrhizal infection as influenced by tillage and soil phosphorus. Journal of Plant Nutrition. 10, 1349-1356.

Anderson, R.C., Liberta, A.E., Dickman, L.A., Katz, A.J. 1983. Spatial variation in vesicular-arbuscular mycorrhiza spore density. Bulletin of Torrey Botanical Club. 110, 519-525.

Bagyaraj, D.J. 1991. Ecology of vesicular arbuscular mycorrhizae, in: D.K. Arora, B. Rai, K.G. Mukerji, G.R. Knudsen (Eds.), Handbook of applied mycology: soil and plants. Marcel Dekker, Inc., New York, pp. 3-34.

Bellgrad, S.E. 1993. The topsoil as the major store of propagules of vesicular-arbuscular mycorrhizal fungi in southeast Australian sandstone soils. Mycorrhiza. 3, 19-24.

Brady, N.C., Weil, R.R. 1996. The Nature and Properties of Soils. Prentice-Hall, Upper Saddle River, NJ, USA.

Brundrett, M.C. 2002. Coevolution of roots and mycorrhizas of land plants. New Phytologist. 154, 275-304.

Copetta, A., Lingua, G., Berta, G. 2006. Effects of three AM fungi on growth, distribution of glandular hairs and essential oil production in Ocimum basilicum L. var. Genovese. Mycorrhiza. 16, 485-494.

Cuenca, G., Lovera, M. 2010. Seasonal variation and distribution at different soil depths of Arbuscular Mycorrhizal fungi spores in a tropical sclerophyllous shrubland. Botany. 88, 54-64

Dubey, A., Singh, P.K., Mishra, M.K., Vyas, D. 2008. Occurrence of AM fungi at varying stages of growth of rice plants. Proceedings of the National Academy of Sciences, India, Section B. 78, 45-48. 
Friese, C.F., Koske, R.E. 1991. The spatial dispersion of spores of vesicular arbuscular mycorrhizal fungi in a sand dune: micro-scale patterns associated with the root architecture of American beach grass. Mycolological Research. 95, 952-957.

Gerdemann, J.W., Nicolson, T.H. 1963. Spores of mycorrhizal Endogone species extracted from soil by wet sieving and decanting. Transactions of British Mycological Society. 46, 235-244.

Habte, M. 1999. Soil acidity as a constraint to the application of arbuscular mycorrhizal technology, in: A. Varma, B. Hock (Eds.), Mycorrhiza 2nd ed. Springer-Verlag, Berlin, Germany, pp. 557-569.

Jakobsen, I., Nielsen, N.E. 1983. Vesicular arbuscular mycorrhiza in field-grown crops I. Mycorrhizal infection in cereals and peas at various times and soil depths. New Phytologist. 93, 401-413.

Jansa, J.A., Mozafar, A., Anken, T., Ruh, R., Sanders, I.R., Frossard, E. 2003. Soil tillage affects the community structures of mycorrhizal fungi in maize roots. Ecological Applications. 13, 11641176.

Jha, A., Kumar, A., Saxena, R.K., Kamalvanshi, M., Chakravarty, N. 2011. Effect of arbuscular mycorrhizal inoculations on seedling growth and biomass productivity of two bamboo species. Indian Journal of Microbiology. 52, 281-285.

Kapoor, L.D. 2005. Handbook of Ayurvedic Medicinal Plants. Boca Raton, Florida.

Karaarslan, E., Uyanoz, R. 2011. Occurrence of arbuscular mycorrhizal fungi in some native plants grown on saline soils around the lake Tuz in Turkey and its relations with some physical and chemical properties of soil. Scientific Research and Essays. $6,4238-4245$

Khade, S.W., Bukhari, M.J., Jaiswal, V., Gaonkar, U.C., Rodrigues, B.F. 2002. Arbuscular mycorrhizal status of medicinal plants: a field survey of AM fungal association in shrubs and trees. Journal of Economics and Taxonomic Botany. 26, 571-578.

Khare, C.P. 2004. Encyclopedia of Indian Medicinal Plants. Springer-Verlag, Berlin Heidelberg, New York.

Kumar, A., Mangla, C., Aggarwal, A., Parkash, V. 2010. Arbuscular mycorrhizal fungal dynamics in the rhizospheric soil of five medicinal plant species. Middle-East Journal of Scientific Research. 6, 281-288.

Kumar, V.M., Mahadevan, A. 1984. The secondary substance inhibits mycorrhizal association. Current Science. 53, 377-378.

Land, S., Schonbeck, F. 1991. Influence of different soil types on abundance and seasonal dynamics of vesicular-arbuscular mycorrhizal fungi in arable soils of north Germany. Mycorrhiza. 1, 39-44.

Mader, P., Fliessabach, A., Dubois, D., Gunst, L., Fried, P., Niggli, U. 2002. Soil fertility and biodiversity in organic farming. Science. 296, 1694-1697.

Meyer, A.H., Botha, A., Valentine, A.J., Acher, E., Louw, P.J.E. 2005. The occurrence and infectivity of arbuscular mycorrhizal fungi in inoculated and uninoculated rhizosphere soils of two-year-old commercial grapevines. South African Journal for Enology and Viticulture. 26, 90-94.

Mishra, M., Singh, P.K., Vyas, D. 2011. Mycorrhiza in medicinal plants. Mycorrhiza News. 23, 14-21.

Misra, A., Gupta, M.L. 2010. Investigation of symbiosis between VAM fungi and root of Patchouli (Pogostemum cablin Bent.). Journal of Microbiology and Antimicrobials. 2, 55-56.

Muthukumar, T. Senthilkumar, M. Rajangam, M. Udaiyan, K. 2006. Arbuscular mycorrhizal 
morphology and dark septate fungal associations in medicinal and aromatic plants of Western Ghats, Southern India. Mycorrhiza. 17, 11-24.

Oehl, F., Sieverding, E., Ineichen, K., Mader, P., Boller, T., Wiemken, A. 2003. Impact of land use intensity on the species diversity of arbuscular mycorrhizal fungi in agroecosystems of central Europe. Applied Environment and Microbiology. 69, 2816-2824.

Oehl, F., Sieverding, E., Ineichen, K., Mader, P., Dubos, D., Boller, T., Wiemken, A. 2004. Impact of long-term conventional and organic farming on the diversity of arbuscular mycorrhizal fungi. Oecologia. 138, 574-583.

Oehl, F., Sieverding, E., Ineichen, K., Ris, E.A., Boller, T., Wiemken, A. 2005. Community structure of arbuscular mycorrhizal fungi at different soil depths in extensively managed agroecosystems. New Phytologist. 165, 273-283.

Oehl, F., Sieverding, E., Palenuela, J., Ineichen, K., da Silva, G.A. 2011. Advances in Glomeromycota taxonomy and classification. IMA Fungus 2, 191199.

Oehl, F., Souza, F.A., Sieverding, E. 2008. Revision of Scutellospora and description of five new genera and three new families in the arbuscular mycorrhiza-forming forming Glomeromycetes from Swiss agricultural fields. Mycotaxon. 106, 311-360.

Opik, M., Moora, M., Liira, J., Zobel, M. 2006. Composition of root-colonizing arbuscular mycorrhizal fungal communities in different ecosystems around the globe. Journal of Ecology. 94, 778-790.

Panwar, J., Tarafdar, J.C. 2006. Distribution of three endangered medicinal plant species and their colonization with arbuscular fungi. Journal of Arid Environments. 65, 337-350.
Peat, H.J., Fitter, A.H. 1993. The distribution of arbuscular mycorrhizas in the British flora. New Phytologist. 125, 845-854.

Radhika, K.M., Rodrigues, B.F. 2010. Arbuscular mycorrhizal fungal diversity in some commonly occurring medicinal plants of Western Ghats, Goa region. Journal of Forestry Research. 21, 45-52.

Richards, L.A. 1954. Diagnosis and Improvement of Saline and Alkali Soils. USDA Handbook No. 60.

Schellenbaum, L., Müller, J., Boller, T., Wiemken, A., Schuepp, H. 1998. Effects of drought on nonmycorrhizal and mycorrhizal maize: changes in the pools of non-structural carbohydrates, in the activities of invertase and trehalase, and in the pools of amino acids and imino acids. New Phytologist. 138, 59-66.

Sehgal, J.L., Mandal, D.K., Mandal, C., Vadivelu, S. 1990. Agroecological Regions of India. National Bureau of Soil Survey and Land Use Planning, Technical Bulletin, Nagpur, India.

Shannon, C.E., Weaver, W. 1946. The Mathematical Theory of Communication. University of Illinois Press, Urbana, IL.

Shukla, A., Kumar, A., Jha, A., Ajit, Rao, D.V.K.N. 2012a. Phosphorus threshold for arbuscular mycorrhizal colonization of crops and tree seedlings. Biology and Fertility of Soils. 48, 109-116.

Shukla, A., Kumar, A., Jha, A., Chaturvedi, O.P., Prasad, R., Gupta, A. 2009. Effects of shade on arbuscular mycorrhizal colonization and growth of crops and tree seedlings in Central India. Agroforestry Systems. 76, 95-109.

Shukla, A., Kumar, A., Jha, A., Dhyani, S.K., Vyas, D. 2012b. Cumulative effects of tree based intercropping on arbuscular mycorrhizal fungi. Biology and Fertility of Soils. 48, 899-909. 
Shukla, A., Kumar, A., Jha, A., Salunkhe, O., Vyas, D. 2012c. Soil moisture levels affect growth and mycorrhization of agroforestry plants. Biology and Fertility of Soils. (10.1007/s00374-012-0744-8).

Smith, S.E., Read, D.J. 2008. Mycorrhizal Symbiosis. Academic Press, London.

Soni, P.K., Vyas, D. 2007. Arbuscular mycorrhizal association with important medicinal plants of Sagar. Indian Phytopathology. 60, 52-57.

Sturmer, S.L., Siqueira, J.O. 2011. Species richness and spore abundance of arbuscular mycorrhizal fungi across distinct land uses in Western Brazilian Amazon. Mycorrhiza. 21, 255-267.

Udaiyan, K., Karthikeyan, A., Muthukumar, T. 1996. Influence of edaphic and climatic factors on dynamics of root colonization and spore density of vesicular-arbuscular Mycorrhizal fungi in Acacia farnesiana Willd. and $A$. planifrons W. et. A. Trees. $11,65-71$.
Verma, N., Tarafadar, J.C., Shrivastava, K.K. 2010. Periodic changes in Prosopis cineraria associated AM population at different soil depth and its relationship with organic carbon and soil moisture. African Journal of Microbiology. 4, 115-121.

Yang, F.Y., Li, G.Z., Zhang, D.E., Christie, P., Li, X.L., Gai, J.P. 2010. Geographical and plant genotype wweffects on the formation of arbuscular mycorrhiza in Avena sativa and Avena nuda at different soil depths. Biology and Fertility of Soils. 46, 435-443.

Zajicek, J.M., Hetrick, B.A.D., Owensby, C.E. 1986. The influence of soil depth on mycorrhizal colonisation of forbes in the tallgrass prarie. Mycologia. 78, 316-320.

Zubek, S., Blaszkowski, J. 2009. Medicinal plants as hosts of arbuscular mycorrhizal fungi and dark septate endophytes. Phytochemical Review. 8, 571-580. 